\title{
Hereditary CD4+ T lymphocytopenia
}

Serem Freier, Eitan Kerem, Zvi Dranitzki, Michael Schlesinger, Ruth Rabinowitz, Chaim Brautbar, Mahmoud Ashkirat, Yaakov Naparstek

Department of Pediatrics, Shaare Zedek Medical Center, Jerusalem, Israel S Freier

E Kerem

Department of Internal Medicine, Hadassah University Hospital, Jerusalem, Israel

Z Dranitzki

Y Naparstek

Hubert H Humphrey Center for

Experimental

Medicine and Cancer

Research, Hebrew

University-Hadassah

Medical School,

Jerusalem, Israel

M Schlesinger

R Rabinowitz

Tissue Typing Laboratory, Hadasssah University Hospital, Jerusalem, Israel

C Brautbar

Worker's Sick Fund Clinic, Sheikh Jarrah, Jerusalem, Israel M Ashkirat

Correspondence to: Professor Serem Freier, Laboratory of Mucosa Immunology, Shaare Zedek Medical Center, POB 3235, Jerusalem, Israel.

Accepted 13 November 1997

Table 1 Lymphocyte surface antigens (per cent of cells)

\begin{tabular}{|c|c|c|c|c|c|c|}
\hline Cell & Normal & Patient 1 & Patient 2 & $\begin{array}{l}\text { Healthy } \\
\text { brother }\end{array}$ & Mother & Father \\
\hline \multicolumn{7}{|l|}{$\mathrm{T}$ cells } \\
\hline CD3 & $68-82$ & 74 & 33 & 73 & 69 & 69 \\
\hline$\alpha \beta$ & & 59 & 30 & 67 & 63 & 69 \\
\hline$\gamma \delta$ & & 10 & 3 & 4 & 4 & \\
\hline $\mathrm{CD} 4$ & $29-55$ & 16 & 16 & 46 & 38 & 49 \\
\hline CD8 & $20-36$ & 59 & 33 & 30 & 35 & 29 \\
\hline CD4:CD8 & $2: 1$ & 0.3 & 0.5 & 1.5 & 1 & 1.7 \\
\hline \multicolumn{7}{|l|}{$\mathrm{B}$ cells } \\
\hline CD19 & $5-15$ & 75 & 7 & 9 & 7 & \\
\hline CD20 & & 11.6 & 15.9 & 13.2 & 8 & \\
\hline \multicolumn{7}{|l|}{ Natural killer cells } \\
\hline CD16 & $10-25$ & 14 & 47 & 15 & 18 & 13 \\
\hline CD56 & $10-25$ & 26 & 47 & 15 & 18 & 13 \\
\hline CD57 & & 45 & 44.5 & 18 & 35 & 26 \\
\hline HLA-DR & $7-20$ & 32 & 23 & 13 & 23 & 19 \\
\hline$\frac{\mathrm{CD} 4+\mathrm{CD} 45 \mathrm{RO}+}{\mathrm{CD} 4+}$ & & 98 & 87 & 59 & 73 & 86 \\
\hline$\frac{\mathrm{CD} 4+\mathrm{CD} 45 \mathrm{RA}+}{\mathrm{CD} 4+}$ & & 0.04 & 13 & 24 & 13 & 7.5 \\
\hline
\end{tabular}

Keywords: CD4+ lymphocytopenia; immunodeficiency; common variable immunodeficiency

We describe here two siblings with CD4+ lymphocytopenia in whom the aetiology seems to be hereditary.

\section{Case reports}

CASE 1

This boy was born in November 1981 to a Palestinian Arab family. His parents are first cousins. There are six siblings who are well and one sister who is similarly affected (case 2). A diminished appetite, failure to gain weight, and intermittent diarrhoea were first noticed at 6 months and have persisted to this day. He has severe learning difficulties, has control of his sphincters, possesses a very limited vocabulary, and can neither read nor write. He has an anxious appearance, microcephaly, dry hair, mild exophthalmos, micrognathus, a high arched palate, protuberant ears, and a short neck. There are no signs of puberty. Peripheral lymph nodes were palpable. The spleen was not enlarged. He has bilateral bronchiectasis and pansinusitis. He is clubbed and has extensive warts at the backs of both hands and lenticular opacities in both eyes.

Alkaline phosphatase, $\gamma$-glutamyltransferase, alanine aminotransferase, and aspartate amino- transferase have been raised throughout 10 years of follow up. He was persistently positive for hepatitis B surface antigen. $\mathrm{He}$ is positive for hepatitis e antigen but has no corresponding antibodies. He had persistent intestinal infection with salmonella, campylobacter, shigella, and Giardia lamblia and evidence of chronic non-specific colitis. \begin{abstract}
crease in the population of $\mathrm{CD} 4+$ helper $\mathrm{T}$ cells.

(Arch Dis Child 1998;78:371-372)

Two siblings suffering from mental retarsive warts, and persistent hepatitis $B$ are described. The propositus also had an unusual physiognomy and non-specific
\end{abstract}

CASE 2

The 18 year old sister of case 1 has minor learning difficulties. She can read and write with difficulty. She also has bronchiectasis, pansinusitis, warts at the backs of both hands, and is positive for hepatitis B surface antigen. There was no splenomegaly.

\section{Immunological investigations}

Both patients suffered from an absolute lymphocytopenia with lymphocyte counts frequently below 1200 cells/ $\mu$ l. Stimulation of T cells with phytohaemagglutinin, concanavalin A, and pokeweed mitogen varied from normal to low in patient 1 and was low in patient 2 . Red blood cell adenosine deaminase and purine nucleoside phosphorylase were normal in patient 1 . IgG, IgA, IgM, and IgG subclasses were normal in both patients. They also had antibodies to yersinia, pertussis, and streptolysin $\mathrm{O}$ and to numerous viruses. Antibodies to HIV were measured in both patients on three occasions during a three year period and found to be negative. Antinuclear factor speckled antibodies were found repeatedly in patient 1. Numerous other autoantibodies were absent.

The total number of $\mathrm{T}$ lymphocytes, assessed by their reactivity with anti-CD 3 monoclonal antibody (MoAb) was below normal in patient 2 but normal in all other members of the family including patient 1 (table 1 ).

Results similar to those obtained with anti-CD3 MoAb were obtained when the sum of lymphocytes expressing either $\alpha \beta$ or $\gamma \delta$ cell receptors was calculated. The proportion of CD4+ cells was below normal in the two patients, but within the normal range in other members of the family. The CD4:CD8 ratio was markedly decreased in the two patients and somewhat reduced in the mother. The majority of the CD4+ cells displayed the "memory" phenotype (CD4+CD45RO+) in all members of the family. This was particularly pronounced in patient 1 in whom practically all of the CD4+ cells had the "memory" phenotype and none had the "naive" (CD4+CD45RA+) phenotype. In patient 2 , in whom the level of $\mathrm{T}$ cells was markedly diminished, the population of natural killer cells was significantly increased. This was manifested by a marked 
increase of the proportion of CD16+ and CD56+CD3- cells. The proportion of B lymphocytes expressing the CD19 and CD20 markers was normal in all members of the family.

\section{Discussion}

Non-HIV related CD4+ lymphocytopenia has been recognised for the last 10 years, but as it probably is not a single nosological entity the exact classification of our patients' disease is a matter for discussion. The criteria for the diagnosis of CD4+ lymphocytopenia include: less than $300 / \mu \mathrm{l}$ of CD $4+\mathrm{T}$ cells or less than $20 \%$ of the peripheral blood lymphocytes in at least two measurements, no evidence of HIV infection, or other immunodeficiency, and no history of administration of immunosuppressive drugs. ${ }^{1}$ Both patients fulfilled these criteria.

Clinically, the manifestations of CD4+ lymphopenia range from no symptoms to mild or even opportunistic infections such as histoplasmosis and cytomegalovirus. ${ }^{1}$ We have found no account of a familial incidence of CD4+ lymphopenia in the literature and suggest that the patients described here may represent a previously unnoticed symptom complex including mental retardation, pansinusitis, bronchiectasis, and warts. Immunologically, they had CD4+ lymphocytopenia, with increased markers of activation (DR;CD57) and "memory" (CD4+CD45RO+) and decreased function of cell mediated immunity. In addition, the male sibling had a peculiar physiognomy, non-specific colitis, persistent hepatitis $\mathrm{B}$, and speckled antinuclear antibodies. It should be noted that our patients did not have opportunistic infections and, therefore, do not fulfill the criteria for primary $\mathrm{CD} 4+\mathrm{T}$ cell deficiency as defined by the report of the World Health Organisation (WHO) Scientific Group on immunodeficiency diseases. ${ }^{2}$

Another condition which must be considered is common variable immunodeficiency (CVID). This is a heterogeneous group of conditions characterised by hypogammaglobulinaemia, recurrent bacterial infections, and various immunological abnormalities. Some patients have a reduced CD4/CD8 ratio and thus may resemble the patients described by us. In CVID, however, serum IgG and IgA concentrations are usually deceased. ${ }^{2} 3$

The immunoglobulin concentrations were normal on repeated investigations. Both our patients had antibodies to bacterial and viral antigens, yet these were not sufficient to ward off purulent, bacterial infections and bronchiectasis, as well as extensive warts on the extensor aspects of the hands presumably caused by papilloma virus.

There was no splenomegaly thus excluding the category of CVID with splenomegaly ${ }^{3}$ nor did the children have the facial anomalies described in the immunodeficiency, centromeric instability, and facial anomalies syndrome. Furthermore, CD4+ deficiency secondary to infection with hepatitis $\mathrm{C}$ has been excluded, as no hepatitis $\mathrm{C}$ antibodies were detected. ${ }^{4} \mathrm{CD} 4+\mathrm{T}$ cell deficiency is also a feature of the bare lymphocyte syndrome ${ }^{5}$ and of hereditary absence of the T4 epitope. ${ }^{6}$ Our patients do not fit the criteria of either of these syndromes. In the WHO report ${ }^{2}$ allowance is made for the fact that new clinical forms of immunodefiency and associated syndromes will be described in the course of time. We believe that we have described one such entity.

This study was supported by grants from the Miriam This study was supported by grants from the Miriam
Coven-Fish Foundation and from the F Goldhirsch Foundation.

\footnotetext{
1 Lobato MN, Spira TJ, Rogers MF and the Laboratory Task Force. CD4+ lymphocytopenia in children: lack of evidence for a new acquired immunodeficiency syndrome agent. Pediatr Infect Dis f 1995;14:527-35.

2 Report of a WHO Scientific Group. Primary immunodeficiency diseases. Clin Exp Immunol 1997;suppl 1.

ciency diseases. Clin Exp Immunol 1997;suppl 1.
Sneller MC, Strober W, Eisenstein E, Jaffe JS, CunninghamSneller MC, Strober W, Eisenstein E, Jaffe JS, Cunningham-
Rundles C. New insights into common variable immunoRundles C. New insights into common variabl
deficiency. Ann Intern Med 1993;118:720-30.

4 Paolini R, D'Andrea E, Poletti A, Del Mistro A, Zerbinati P, Girolami A. B Non-Hodgkin's lymphoma in a hemophilia patient with idiopathic CD4+ T-lymphocytopenia. Leuk Lymphoma 1996;21:177-80.

5 Klein C, Lisowska-Grospierre B, LeDeist F, Fischer A, Griscelli C. Major hisyocompatibility complex class II deficiency: clinical manifestations, immunologic features and outcome. F Pediatr 1993;123:921-8.

6 Bach M-A, Phan-Dinh-Tuy F, Bach J-F, et al. Unusual phenotypes of human inducer T cells as measured by OKT4 and related monoclonal antibodies. F Immunol 1981;127: $980-2$.
} 